\title{
Magnetic and Photocatalytic Behaviors of Ca Mn Co-Doped $\mathrm{BiFeO}_{3}$ Nanofibres
}

\author{
Yannan Feng, Huanchun Wang, Yang Shen, Yuanhua Lin ${ }^{*}$, Cewen Nan \\ State Key Laboratory of New Ceramics and Fine Processing, School of Materials Science and Engineering, \\ Tsinghua University, Beijing, China \\ Email: *linyh@tsinghua.edu.cn
}

Received May 29, 2013; revised June 29, 2013; accepted August 1, 2013

Copyright (C) 2013 Yannan Feng et al. This is an open access article distributed under the Creative Commons Attribution License, which permits unrestricted use, distribution, and reproduction in any medium, provided the original work is properly cited.

\begin{abstract}
$\mathrm{Ca}$ and $\mathrm{Mn}$ co-doped $\mathrm{BiFeO}_{3}$ ultrafine nanofibres were prepared with the purpose of improving magnetic and photocatalytic performances of the one-dimensional multiferroic material. Impurity phase introduced by both Bi fluctuation and $\mathrm{Mn}$ substitution can be suppressed by $\mathrm{Ca}$ doping and a space group transition from R3c to C222 can also be triggered by Bi-site doping. With co-substitution of $\mathrm{Mn}$ into iron site, the $\mathrm{Ca}_{0.15} \mathrm{Bi}_{0.85} \mathrm{Mn}_{0.05} \mathrm{Fe}_{0.95} \mathrm{O}_{3}$ nanofibres presented a larger saturation magnetization than the singly $\mathrm{Ca}$ doping samples, possibly due to the increased double exchange interation of $\mathrm{Fe}^{3+}-\mathrm{O}-\mathrm{Fe}^{2+}$, strengthened by $\mathrm{Ca}$ and $\mathrm{Mn}$. Photocatalytic degradation test witnessed a similar drop-and-rise performance with the magnetism.
\end{abstract}

Keywords: Bismuth Ferrite; Nanofibre; Magnetic; Photocatalytic

\section{Introduction}

Bismuth ferrite $\left(\mathrm{BiFeO}_{3}\right.$, or $\left.\mathrm{BFO}\right)$, one of the most widely researched multiferroics, has continuously proved to be a remarkable attraction, due to its room temperature antiferromagnetic and ferroelectric orderings, [1] high visible light response, and consequent potentiality in multifunctional devices [2,3] and polluted water remediation [4]. In order to promote the performance of BFO, a variety of nanostructures have been fabricated [5-7] and a number of ions have been utilized as dopants, including rare earth metals, [8] transition metals [9] and alkaline earth metals [10]. However, unified theory can still be a rather difficult issue, because the property is delicately subject to both strain effect and doping effect. Therefore, systematic study focused on one nanostructure and one doping element is desired. La, Ca singly doped BFO nanofibres have been synthesized previously and studied detailedly $[7,11]$. They did show enhanced behaviors in magnetic and photocatalytic aspects, however none of these individual dopants was able to modulate the properties ideally and arbitrarily. Given this fact, co-doping has been proposed as an option. Some recent progress in nanofibre preparation [12] has already demonstrated the significance of co-doping and it is hence in urgent need of extensive studies.

*Corresponding author.
In this work, we fixed Mn doping content to 0.05 and varied $\mathrm{Ca}$ concentration, in the hope of obtaining one-dimensional BFO nanofibres equipped with more excellent capacity and exploring the interaction between dopants in different doping sites.

\section{Experimental}

$\mathrm{Ca} \mathrm{Mn}$ co-doped BFO $\left(\mathrm{Ba}_{\mathrm{x}} \mathrm{Bi}_{1-\mathrm{x}} \mathrm{Fe}_{0.95} \mathrm{Mn}_{0.05} \mathrm{O}_{3}\right)$ ultrafine fibres with four Ca doping contents $(\mathrm{x}=0, \mathrm{x}=0.05, \mathrm{x}=$ $0.10, \mathrm{x}=0.15)$ were synthesized through a sol-gel based electrospinning method. Precursor solution was prepared with bismuth nitrate $\left(\mathrm{Bi}\left(\mathrm{NO}_{3}\right)_{3} \cdot 5 \mathrm{H}_{2} \mathrm{O}\right)(5 \mathrm{~mol} \%$ excess to compensate for $\mathrm{Bi}$ loss during the heat treatment in air), iron nitrate $\left(\mathrm{Fe}\left(\mathrm{NO}_{3}\right)_{3} \cdot 9 \mathrm{H}_{2} \mathrm{O}\right)$, and calcium nitrate $\left(\mathrm{Ca}\left(\mathrm{NO}_{3}\right)_{2} \cdot 4 \mathrm{H}_{2} \mathrm{O}\right)$ and $50 \mathrm{wt} \% \%$ manganous nitrate solution $\left(\mathrm{Mn}\left(\mathrm{NO}_{3}\right)_{2}\right)$. Mixed together with the complexant, citric acid $\left(\mathrm{C}_{6} \mathrm{H}_{8} \mathrm{O}_{7}\right)$ in the solvent $\mathrm{N}$, N-Dimethylfomamide (DMF, $\mathrm{C}_{3} \mathrm{H}_{7} \mathrm{NO}$ ), the homogeneous solution was placed in the shade for $24 \mathrm{~h}$ aging. Afterwards, polyvinylpyrrolidone (PVP, M = 1,300,000) was added to the mixture solution, which was then continuously stirred till PVP completely dissolved. Subsequently electrospinning process was initiated by loading the ropy precursor solution into a syringe with its stainless-steel needle uploaded with high voltage $(13 \mathrm{kV})$. The rotating cylinder collector $10 \mathrm{~cm}$ away was grounded, and a static electric field of 
$1.3 \mathrm{kV} / \mathrm{cm}$ intensity was thus built across. The thick hybrid was squeezed out, drawn into ultrafine nanofibre and started vibrating after going straight a little while, due to the extremely high tension, which prolonged spun duration and assured DMF volatilized thoroughly. The nonvolatile, mainly the complex compound, remained on PVP fibres which later weaved on an aluminium foil. These as-spun fibres went through a heating process of $90 \mathrm{~min}$ presintering at $420^{\circ} \mathrm{C}$, and $3 \mathrm{~h}$ calcination at $580^{\circ} \mathrm{C}$

X-ray diffraction (short for XRD) (Rigaku $\mathrm{D} / \max 2500$ ) with $\mathrm{Cu} \mathrm{K} \mathrm{K}_{\alpha}(0.15418 \mathrm{~nm})$ was utilized to analyze the phase structure. Magnetic behaviors were observed in physical property measurement system (PPMS-9T). Field emission scan electron microscope (FESEM) (JSM7001F) was employed in the microstructure measurement, and atom arrangement was approached with high resolution transmission electron microscope (HRTEM) (JOEL2011). Ultraviolet-visible (UV-Vis) curves were tested in Hitachi U3310 spectrophotometer, while photocatalytic performance was carried out under self-made reaction and test system. The degradation of CR was determined by the intensity of the absorption peak of CR $(495 \mathrm{~nm})$ relative to its initial value $\left(\mathrm{C} / \mathrm{C}_{0}\right)$.

\section{Result and Discussion}

Results of phase structure analysis are shown in Figure 1. Some typical peaks for nonstoichiometric phases can be detected, which are possibly from $\mathrm{Bi}_{3.43} \mathrm{Fe}_{0.57} \mathrm{O}_{6}$ and $\mathrm{Bi}_{25} \mathrm{FeO}_{40}$. Apart from these impurity peaks, all the other could be ascribed to the main phase, $\mathrm{BiFeO}_{3}$, JCPDS Card No.86 - 1518. High crystallity could be proved by the sharp peak shape, and mergers of the doublet peaks, for instance, (104) and (110), (006) and (202), (116) and (122), (214) and (300), indicate a structural transition of space group and symmetry can be obtained by Ca doping, while Mn doping might introduce more impurities, similar phenomenon has been reported previously [13]. As

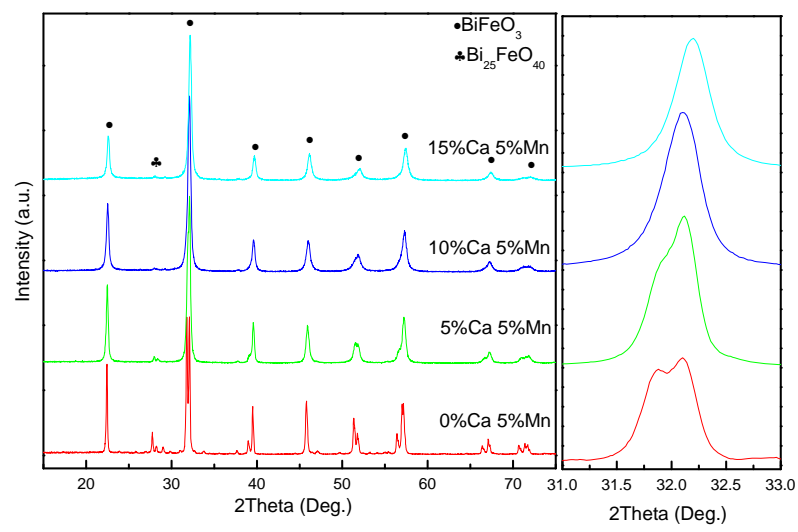

Figure 1. XRD patterns for pristine and doped BFO nanofibres. And slow scan spectra near $32^{\circ}$.
$\mathrm{Ca}$ content grows, the peaks shifts to higher angle, indicating the shrinkage of the crystal lattice.

Morphology and microstructure of these nanofibres were observed and the results are shown in Figure 2. As spun samples have an average diameter of $140 \mathrm{~nm}$ and they are smooth in shape, owing to the polymer nature of carrier PVP. However, after sintering process, the average diameter shrank to below $120 \mathrm{~nm}$ and the morphology turned to be coarse. From the HRTEM image, we can find that sunken area might be the grain boundary zone and the adjacent grains stagger quite slightly in crystal orientation probably because of the one-dimensional restraint condition. In the surface area, looser atom arrangement and different lattice plane can be observed, compared with the inside bulk zone.

Mn co-doping might endowed these nanofibres enormous impact on the thermal property and structure. In fact, our previous study [11] showed that an annealing temperature of $660^{\circ} \mathrm{C}$ or a little lower was ideal for singly doped BFO nanofibres. In this co-doping case, we had to reduce the sintering temperature to $580^{\circ} \mathrm{C}$ to keep the nanofibre shapes unbroken, though Mn concentration was as little as $5 \%$.

Magnetic properties of the as-prepared nanofibres are graphed in Figure 3. When $\mathrm{Mn}$ is the only dopant, we can see that the fibres show good magnetism with high saturation magnetization, evident remnant magnetization and coercive force. However, when $\mathrm{Ca}$ was doped into the fibres, situation changed with a dramatic drop of both saturation magnetization and coercive force. This downgrading trend stops and turns upwards later with incremental $\mathrm{Ca}$ content, and when $\mathrm{Ca}$ content reaches $10 \%$, saturation magnetization has exceeded that of $5 \% \mathrm{Mn}$ doped sample. We consider the magnetism of $5 \% \mathrm{Mn}$ doped fibres to be originated from the magnetic moment of $\mathrm{Mn}$ itself, the charge compensation effect and the incident impurity phases. Nevertheless, the pop-in of the $\mathrm{Ca}$ might have indirectly conflicted with Mn somehow, for instance, pinned the Mn valence state. Later on, when $\mathrm{Ca}$ becomes majority, its impact on Fe becomes dominating. At this moment, the moment of $\mathrm{Mn}$ can help strengthen the magnetization instead, together with the $\mathrm{Fe}$ valence state variation and $\mathrm{Fe}^{2+}-\mathrm{O}-\mathrm{Fe}^{3+}$ super exchange $[12,14-16]$ caused by $\mathrm{Ca}$ doping. Our previous work has shown saturation magnetization is positively correlated with the $\mathrm{Ca}$ content, [11] while combining with this work, we can infer that Mn should have dual effects, one will be restrained by $\mathrm{Ca}$ doping, that is perhaps charge effect, and the other, which is likely to be residual moment, will cooperate with $\mathrm{Ca}$ on property improvement.

Owing to the superior specific surface area, the catalytic activity is rather worthy to look forward to. Degradation experiment of Congo red has demonstrated the same trend with magnetism variation. As seen from the 


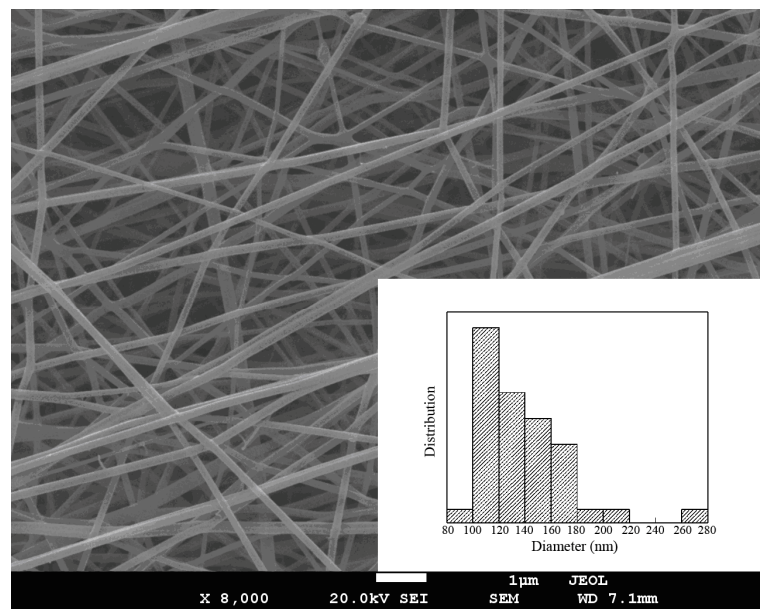

(a)

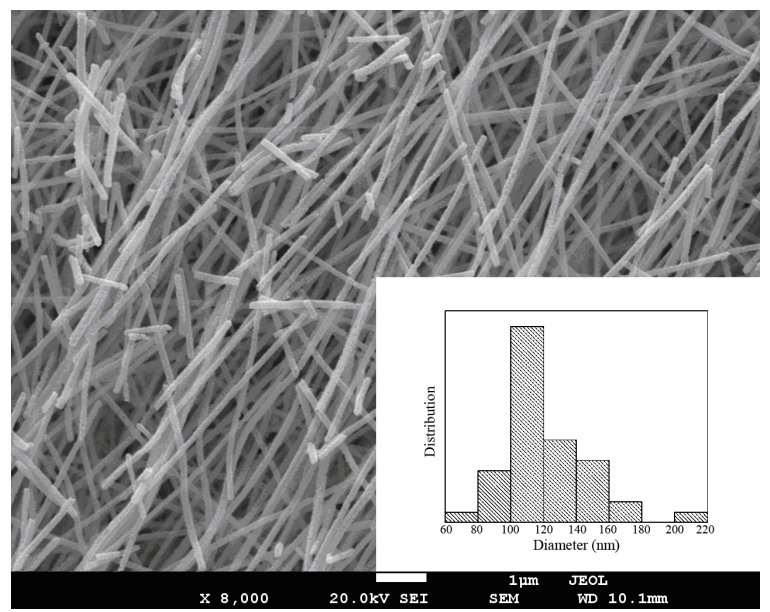

(b)

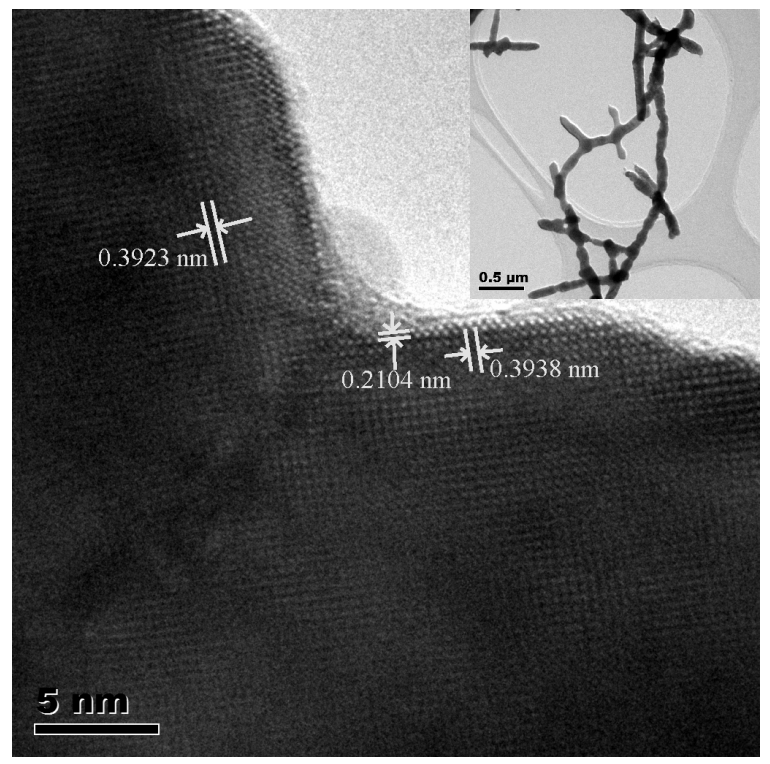

(c)

Figure 2. Morphology and microstructure of BFO nanofibres. SEM image of (a) as spun and (b) sintered sample, and its (c) HRTEM image.

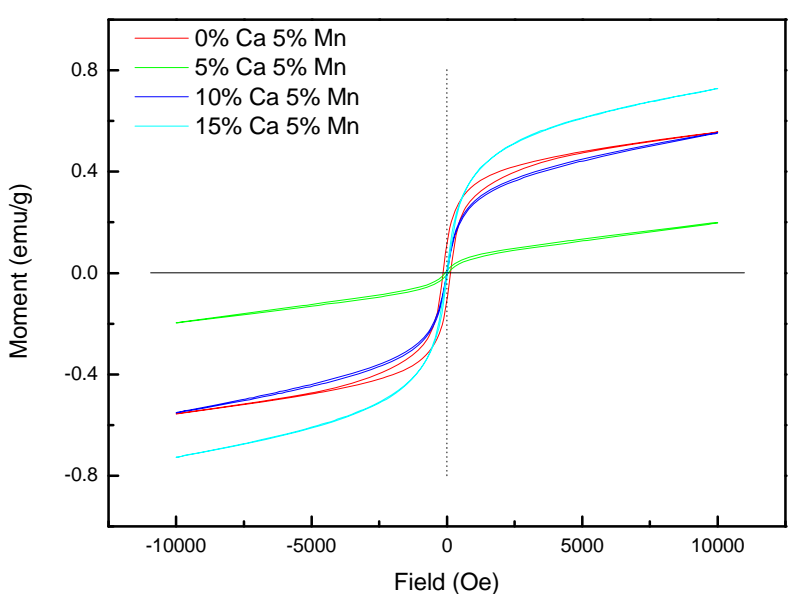

(a)

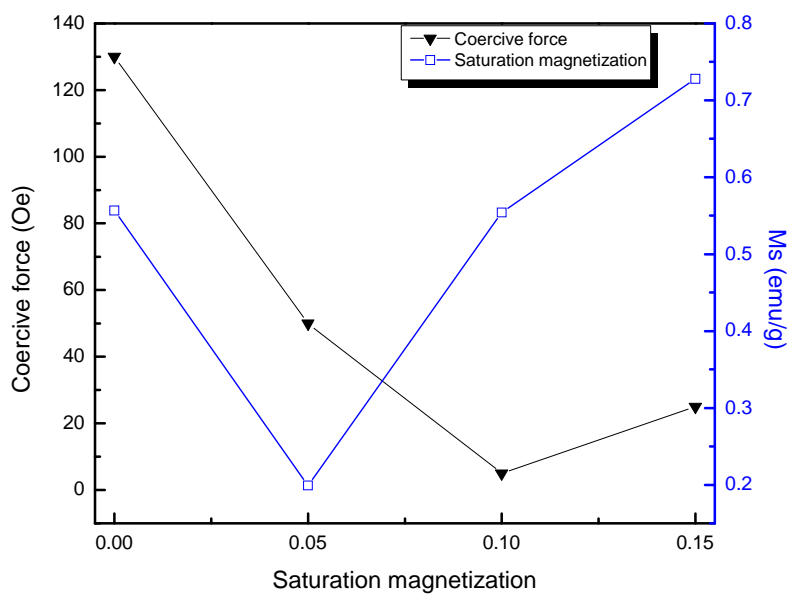

(b)

Figure 3. (a) M-H curves and (b) magnetic properties in a magnetic field with maximum of $10 \mathrm{k}$ Oe at $300 \mathrm{~K}$ (room temperature).

Figure 4, though all samples show good photocatalytic efficiency as a result of considerably large specific surface area and high visible light response, there exists a minimum for photodecomposition. This minimum, arising when the doping concentration is equal, might similarly suggest the mutual weakening effect between $\mathrm{Ca}$ and $\mathrm{Mn}$. When $\mathrm{Ca}$ doping content is more than $5 \%$, photocatalytic degradation shows positive correlation to doping proportion. And with the co-existence of a small amount of $\mathrm{Mn}$, photocatalytic activity is raised markedly and higher than $\mathrm{Ca}$ singly doping. This excellent performance could be explained by increment of free carrier and decreased electron-hole recombination rate, while the excessive activity on the Mn singly doping condition might be attributed to impurity phases and structural influence offered by $\mathrm{Mn}$. In addition, when Mn was brought in the lattice, the bandgap further narrowed down and these nanofibres showed a bit of semi-conductivity, which was consistent with the color change from previous Mn-free samples. We thus assumed that the 


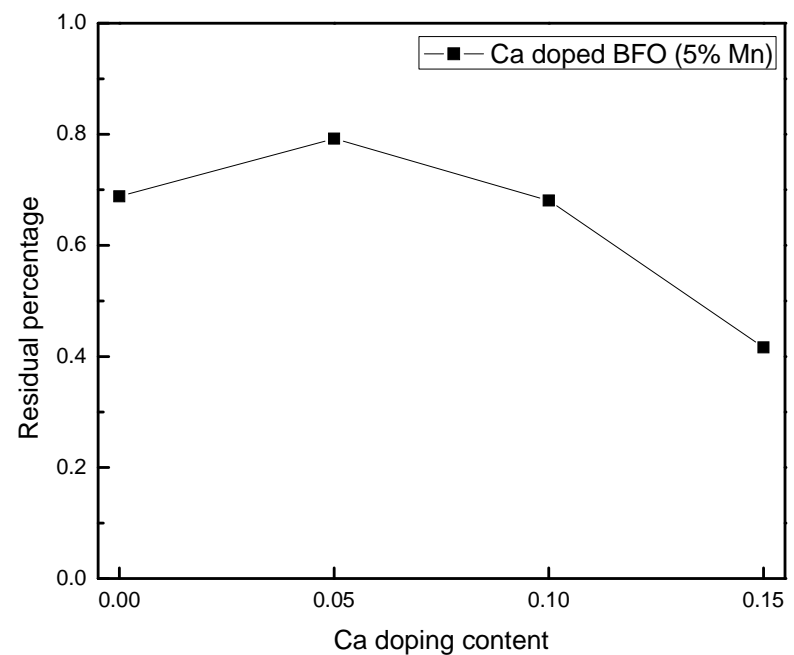

Figure 4. Congro red degradation after 2 h visible light irradiation.

$\mathrm{Ca}$ Mn co-doping might bring many states into $\mathrm{BFO}$ and therefore had immense impact on the catalytic behavior.

\section{Conclusion}

In conclusion, the influence of $\mathrm{Ca} \mathrm{Mn}$ co-doping on phase structure, magnetic and photocatalytic properties of BFO nanofibres was systematically investigated. Mn doping has triggered some impurity which can later be suppressed by $\mathrm{Ca}$ doping, and in this process, a space group transition can be observed. Magnetic and photocatalytic measurement suggested a dual role of $\mathrm{Mn}$, and by this co-doping method, the performances can be enhanced and modulated.

\section{Acknowledgements}

This work was supported by the Ministry of Science and Technology of China through a 973-Project under Grant No. 2009CB623303, NSF of China (51272121 and 5102 $5205)$.

\section{REFERENCES}

[1] G. A. Smolenskii and I. Chupis, "Ferroelectromagnets," Soviet Physics Uspekhi, Vol. 25, No. 7, 1982, pp. 475493. doi:10.1070/PU1982v025n07ABEH004570

[2] T. Choi, S. Lee, Y. J. Choi, V. Kiryukhin and S. W. Cheong, "Switchable Ferroelectric Diode and Photovoltaic Effect in $\mathrm{BiFeO}_{3}$," Science, Vol. 324, No. 5923, 2009, pp. 63-66. doi:10.1126/science.1168636

[3] J. Wang, J. B. Neaton, H. Zheng, V. Nagarajan, S. B. Ogale, B. Liu, D. Viehland, V. Vaithyanathan, D. G. Schlom, U. V. Waghmare, N. A. Spaldin, K. M. Rabe, M. Wuttig and R. Ramesh, "Epitaxial $\mathrm{BiFeO}_{3}$ Multiferroic Thin Film Heterostructures," Science, Vol. 299, No. 5613, 2003, pp. 1719-1722. doi:10.1126/science.1080615

[4] F. Gao, X. Y. Chen, K. B. Yin, S. Dong, Z. F. Ren, F. Yuan,
T. Yu, Z. G. Zou, J. M. Liu and Adv. Mater, "VisibleLight Photocatalytic Properties of Weak Magnetic $\mathrm{BiFeO}_{3}$ Nanoparticles," Vol. 19, No. 19, 2007, pp. 2889-2892. doi:10.1002/adma.200602377

[5] S. Li, Y. H. Lin, B. P. Zhang, Y. Wang and C. W. Nan, "Controlled Fabrication of $\mathrm{BiFeO}_{3}$ Uniform Microcrystals and Their Magnetic and Photocatalytic Behaviors," The Journal of Physical Chemistry C, Vol. 114, No. 7, 2010, pp. 2903-2908. doi:10.1021/jp910401u

[6] X. Xu, Y. H. Lin, P. Li, L. Shu and C. W. Nan, "Synthesis and Photocatalytic Behaviors of High Surface Area $\mathrm{BiFeO}_{3}$ Thin Films," Journal of the American Ceramic Society, Vol. 94, No. 8, 2011, pp. 2296-2299. doi:10.1111/j.1551-2916.2011.04653.x

[7] Z. A. Zhang, H. Y. Liu, Y. H. Lin, Y. Wei, C. W. Nan and X. L. Deng, "Influence of La Doping on Magnetic and Optical Properties of Bismuth Ferrite Nanofibers," Journal of Nanomaterials, Vol. 2012, No. 238605, 2012, pp. 1-5. doi:10.1155/2012/238605

[8] J. Liu, L. Fang, F. Zheng, S. Ju and M. Shen, "Enhancement of magnetization in $\mathrm{Eu}$ doped $\mathrm{BiFeO}_{3}$ nanoparticles," Applied Physics Letters, Vol. 95, No. 2, 2009, pp. 022511-022513. doi:10.1063/1.3183580

[9] P. Kharel, S. Talebi, B. Ramachandran, A. Dixit, V. M. Naik, M. B. Sahana, C. Sudakar, R. Naik, M. S. R. Rao and G. Lawes, "Structural, Magnetic, and Electrical Studies on Polycrystalline Transition-Metal-Doped $\mathrm{BiFeO}_{3}$ Thin Films," Journal of Physics: Condensed Matter, Vol. 21, No. 3, 2009, pp. 036001-036006.

doi:10.1088/0953-8984/21/3/036001

[10] B. Bhushan, A. Basumallick, S. K. Bandopadhyay, N. Y. Vasanthacharya and D. Das, "Effect of Alkaline Earth Metal Doping on Thermal, Optical, Magnetic and Dielectric Properties of $\mathrm{BiFeO}_{3}$ Nanoparticles," Journal of Physics D: Applied Physics, Vol. 42, No. 6, 2009, pp. 065004 065011. doi:10.1088/0022-3727/42/6/065004

[11] Y. N. Feng, H. C. Wang, Y. D. Luo, Y. Shen and Y. H. Lin, "Ferromagnetic and Photocatalytic Behaviors Observed in $\mathrm{Ca}$-Doped $\mathrm{BiFeO}_{3}$ Nanofibres," Journal of Applied Physics, Vol. 113, No. 14, 2013, pp. 146101-146103. doi:10.1063/1.4801796

[12] B. Li, C. Wang, W. Liu, M. Ye and N. Wang, "Multiferroic Properties of $\mathrm{La}$ and $\mathrm{Mn} \mathrm{Co}-$ Doped $\mathrm{BiFeO}_{3}$ Nanofibers by Sol-Gel and Electrospinning Technique," Materials Letters, Vol. 90, 2013, pp. 45-48. doi:10.1016/j.matlet.2012.09.012

[13] H. C. Wang, Y. H. Lin, Y. N. Feng and Y. Shen, "Photocatalytic Behaviors Observed in $\mathrm{Ba}$ and $\mathrm{Mn}$ Doped $\mathrm{BiFeO}_{3}$ Nanofibers," Journal of Electroceramics, 2013, pp. 1-4. doi:10.1007/s10832-013-9818-8

[14] J. Wei and D. Xue, "Effect of Non-Magnetic Doping on Leakage and Magnetic Properties of $\mathrm{BiFeO}_{3}$ Thin Films," Applied Surface Science, Vol. 258, No. 4, 2011, pp. 1373-1376. doi:10.1016/j.apsusc.2011.09.066

[15] F. P. Gheorghiu, A. Ianculescu, P. Postolache, N. Lupu, M. Dobromir, D. Luca and L. Mitoseriu, "Preparation and Properties of $(1-\mathrm{x}) \mathrm{BiFeO}_{3-\mathrm{x}} \mathrm{BaTiO}_{3}$ Multiferroic Ceramics," Journal of Alloys and Compounds, Vol. 506, No. 2, 2010, pp. 862-867. doi:10.1016/j.jallcom.2010.07.098 
[16] Y. Wang and C. W. Nan, "Enhanced Ferroelectricity in Ti-Doped Multiferroic $\mathrm{BiFeO}_{3}$ Thin Films," Applied
Physics Letters, Vol. 89, No. 5, 2006, pp. 052903-052905. doi: $10.1063 / 1.2222242$ 